\title{
Practice advisory: Etanercept for poststroke disability
}

Report of the Guideline Development, Dissemination, and Implementation Subcommittee of the American Academy of Neurology

Gary S. Gronseth, MD

Steven R. Messé, MD

Correspondence to American Academy of Neurology: guidelines@aan.com
Editorial, page 2122

Supplemental data at Neurology.org

\section{ABSTRACT}

Objective: To review evidence regarding the effectiveness, safety, and tolerability of etanercept used to treat patients with poststroke disability.

Methods: We searched MEDLINE and the Cochrane Central Register of Controlled Trials for studies of adult patients with poststroke disability treated with etanercept in order to improve their functional status. We rated each study for risk of bias (Class I-IV) using the American Academy of Neurology therapeutic classification of evidence scheme. Practice recommendations were formulated on the basis of the strength of the evidence and assessments of potential benefits, potential harms, and patient preferences.

Results: Two case series were identified, and both reported clinical improvements 3 weeks following treatment across a wide range of functional domains. However, both studies were rated Class IV because of poor methodologic quality (i.e., high risk of bias).

Conclusions: For patients with poststroke disability, the evidence is insufficient to support or refute a benefit of etanercept for the treatment of poststroke disability.

Recommendations: Clinicians should counsel patients considering etanercept for treatment of poststroke disability that the evidence is insufficient to determine the treatment's effectiveness and that it may be associated with adverse outcomes and high cost (Level U). Neurology ${ }^{\circledR}$ 2016;86:2208-2211

\section{GLOSSARY}

AAN = American Academy of Neurology; $\mathbf{C l}=$ confidence interval; GDDI = Guideline Development, Dissemination, and Implementation Subcommittee; TNF = tumor necrosis factor
Several members of the American Academy of Neurology (AAN) approached the AAN's Guideline Development, Dissemination, and Implementation Subcommittee (GDDI) (see appendices e-1 and e-2 on the Neurology ${ }^{\circledR}$ Web site at Neurology.org) asking for guidance regarding the use of etanercept for the treatment of poststroke disability.

Stroke is a leading cause of major disability. ${ }^{1}$ An inflammatory response may play an important role in ischemic stroke. ${ }^{2}$ Some authors have hypothesized that the cytokine tumor necrosis factor (TNF) may play a role in the mediation of inflammatory changes in the ischemic penumbra. ${ }^{3}$ Etanercept, a fusion protein consisting of the TNF receptor and the Fc portion of immunoglobulin G, inhibits TNF, thereby diminishing neurotoxic TNF-mediated microglia activation that might contribute to poststroke disability. ${ }^{4}$ Moreover, anti-TNF- $\alpha$ blockade has been reported to demonstrate efficacy in stroke animal models. ${ }^{5}$
This practice advisory addresses the following question: For adult patients with poststroke disability, does etanercept administered by any route (compared with no etanercept or placebo) improve functional status? developing this practice advisory, we used the methodologies described in the 2011 edition of the AAN's guideline development process manual as amended, including the process for developing practice advisories. ${ }^{6}$

In June 2013 and again in June 2015, we performed a search of MEDLINE for articles published using the search terms "cerebrovascular disorders" and "etanercept." Search results were filtered through the broad therapeutic clinical query (see appendix e-3 for the specific search strategy employed). The Cochrane Database of Systematic Reviews and the

\section{DESCRIPTION OF THE ANALYTIC PROCESS In}

From the Department of Neurology (G.S.G.), University of Kansas Medical Center, Kansas City; and the Department of Neurology (S.R.M.), University of Pennsylvania School of Medicine, Philadelphia.

Approved by the Guideline Development, Dissemination, and Implementation Subcommittee on November 7, 2015; by the Practice Committee on November 19, 2015; and by the AAN Institute Board of Directors on February 11, 2016.

Go to Neurology.org for full disclosures. Funding information and disclosures deemed relevant by the authors, if any, are provided at the end of the article. 
Cochrane Central Register of Controlled Trials were also searched. A secondary search of the references of selected articles and review articles was performed to identify studies missed by our search strategy.

The titles and abstracts of the identified citations were reviewed for relevance to the clinical question. The full text of potentially relevant articles was retrieved and included in the analysis if the investigators determined functional status in patients with stroke who were treated with etanercept administered by any route. Studies in animals and those with nonEnglish-language abstracts were excluded from the analysis. Both authors, along with members of the AAN GDDI, independently reviewed articles and completed data abstraction forms. Discrepancies were resolved through discussion.

The investigators determined acceptable effect measures to be a change from pretreatment status after etanercept treatment on any measure of functional ability. When possible, 95\% confidence intervals (CIs) were used as the measure of statistical precision.

Studies were rated for their risk of bias using the AAN 4-tiered classification of evidence scheme for therapeutic studies (appendix e-4). After anchoring to the risk of bias rating, we rated our overall confidence in the evidence using a modified Grading, Recommendations Assessment, Development and Evaluation process (appendix e-5). Subsequently, we developed the wording of actionable recommendations and determined the strength of the recommendations after considering the strength of evidence and deductive inferences, risks and benefits, cost, feasibility, and patient preferences (appendix e-6).

A draft of the practice advisory was made available for public comment from January 28, 2014, through February 28, 2014. The draft manuscript was modified in response to some of the comments.

ANALYSIS OF EVIDENCE Our search strategy identified 33 citations. Twenty-nine articles were excluded because they were review articles, did not specifically include patents with stroke, or were performed on animals. We reviewed the full text of 4 potentially relevant articles. One of these articles was a review without primary data, ${ }^{7}$ and one article was a case report of a patient without MRI evidence of a stroke. ${ }^{8}$ Two articles met inclusion criteria. ${ }^{9,10}$

Study design. Both studies were nonmasked retrospective chart reviews that included patients with poststroke disability who received etanercept; one of the studies ${ }^{9}$ included 3 patients with stroke who were consecutively treated, and the second study included 617 patients with stroke. ${ }^{10}$ Because of the open-label design and absence of a control group, both studies were rated Class IV for a high risk of bias.
It is unclear whether the 3 patients in the first study were excluded in the second study. Thus, additional study descriptions will be limited to the larger study.

Patient characteristics. The average age of patients described in the larger study was 65.8 years (1 patient was younger than 18 years). The average time since the stroke was 42 months (range 0.5-419). Twenty-seven percent of the patients had hemorrhagic strokes. No standard measures (e.g., modified Rankin Scale score) were provided on the distribution of poststroke disability. The average time of the patients to walk 20 meters was 57.2 seconds (SD 52.52).

Intervention. All patients were treated with posterior cervical perispinal muscle injections of $25 \mathrm{mg}$ of etanercept followed by Trendelenburg positioning. This approach was based on findings from a rabbit model that suggested perispinal administration results in rapid delivery of large molecules such as etanercept into the CSF through the Batson plexus. ${ }^{5}$

Efficacy. In the larger study, outcomes were presented immediately posttreatment and after 1 and 3 weeks. Fourteen efficacy measures were presented without a description of prespecified primary or secondary outcomes of interest. These measures included a 20meter timed walk, a visual analogue pain assessment, left- and right-hand grip strength, the FAS verbal fluency test, and dichotomous outcomes of improved vs not improved in multiple functional domains (global clinical improvement, motor impairment, spasticity, walking impairments, cognitive impairment, psychologic impairment, sensory impairment, aphasia, and pain). Overall, patients demonstrated significant improvements on all outcome measures, including the immediate posttreatment period measured within minutes after etanercept administration. The patients' 20-meter walking speed immediately improved by 7.5 seconds (95\% CI 5.5-9.5) on average. The percentage of patients immediately improving in the functional domains ranged from $50.2 \%$ (95\% CI 44.3\%-56\%) for pain to $99.3 \%$ (95\% CI 98.3\%-99.7\%) for global clinical improvement. Three-week outcomes were presented in a subset of patients. Improvement was maintained in the majority of these patients on all outcomes at 3 weeks (appendix e-5). Anecdotal instances of benefits sustained more than 3 weeks were described.

Safety and tolerability. Neither study described adverse events following the administration of etanercept.

Conclusion. Because of the high risk of bias in the available studies, there is insufficient evidence to support or refute the efficacy of perispinal etanercept for the treatment of poststroke disability (2 Class IV studies). 
PUTTING THE EVIDENCE INTO A CLINICAL CONTEXT We have very low confidence in the evidence for efficacy of etanercept for poststroke disability because of the high risk of bias of the relevant studies (appendix e-5). The biological plausibility of benefit was judged to be low because of the reported immediate onset of benefit and single administration of a transiently acting medication. Explanations other than the effectiveness of the treatment for the observed improvements include observer expectation, ${ }^{11}$ performance motivation, ${ }^{12}$ regression to the mean, ${ }^{13}$ and the placebo effect. ${ }^{14}$

Although adverse events of etanercept were not described in these studies, serious adverse events are described in studies of patients receiving etanercept for other conditions. ${ }^{15}$ Such events include injection site reactions, reactivation of tuberculosis, reactivation of hepatitis B virus infection, congestive heart failure, demyelinating neurologic disorders, vasculitis, and hematologic disorders such as aplastic anemia and pancytopenia. A recent randomized trial of subcutaneous etanercept $50 \mathrm{mg}$ once weekly for 24 weeks for the treatment of Alzheimer disease reported no significant difference in the adverse event rates between patients treated with placebo and patients treated with etanercept. ${ }^{16}$ However, the study lacked the statistical precision to exclude uncommon, potentially serious adverse events. It is unclear whether the adverse event profile resulting from the recurrent use of etanercept can be generalized to the time-limited perispinal administration used for the treatment of poststroke disability. Given the limitations of the efficacy of the evidence and the potential for serious adverse events, we judge the risk-benefit tradeoffs of etanercept for poststroke disability to be unfavorable.

As of this writing, the cost of a $25-\mathrm{mg}$ vial of etanercept is about $\$ 440$ in US currency. ${ }^{17}$ Additional costs associated with the pretreatment evaluation and administration of perispinal etanercept are likely to be substantially higher.

RECOMMENDATION Clinicians should counsel patients considering etanercept for treatment of poststroke disability that there is insufficient evidence to determine its effectiveness and that the treatment may be associated with adverse outcomes and high cost (Level U).

\section{RECOMMENDATIONS FOR FUTURE RESEARCH}

Research is needed on the effects of etanercept on poststroke disability. To minimize the risk of bias, future studies of etanercept for the treatment for poststroke disability should randomly allocate patients in a masked fashion to active and placebo treatment arms and employ masked, standardized poststroke disability outcome measures.

\section{AUTHOR CONTRIBUTIONS}

Dr. Gronseth: study concept and design, acquisition of data, analysis or interpretation of data, drafting/revising the manuscript, critical revision of the manuscript for important intellectual content, study supervision. Dr. Messé: study concept and design, acquisition of data, analysis or interpretation of data, drafting/revising the manuscript, critical revision of the manuscript for important intellectual content, study supervision.

\section{STUDY FUNDING}

This practice advisory was developed with financial support from the American Academy of Neurology. Authors who serve as AAN subcommittee members or methodologists (G.S.G., S.R.M.) were reimbursed by the AAN for expenses related to travel to subcommittee meetings where drafts of manuscripts were reviewed.

\section{DISCLOSURE}

G. Gronseth serves as an associate editor for Neurology and as an editorial advisory board member of Neurology Now, and receives compensation from the American Academy of Neurology (AAN) for work as the chief evidence-based medicine methodologist. S. Messé is the vice-chair of the Guideline Development, Dissemination, and Implementation Subcommittee of the AAN; has received consulting fees from GlaxoSmithKline for protocol development; has received research support from GlaxoSmithKline, W.L. Gore \& Associates, and the NIH for clinical trials; and has received royalties from UpToDate for published articles. Go to Neurology.org for full disclosures.

\section{DISCLAIMER}

Clinical practice guidelines, practice advisories, systematic reviews, and other guidance published by the American Academy of Neurology and its affiliates are assessments of current scientific and clinical information provided as an educational service. The information (1) should not be considered inclusive of all proper treatments, methods of care, or as a statement of the standard of care; (2) is not continually updated and may not reflect the most recent evidence (new evidence may emerge between the time information is developed and when it is published or read); (3) addresses only the question(s) specifically identified; (4) does not mandate any particular course of medical care; and (5) is not intended to substitute for the independent professional judgment of the treating provider, as the information does not account for individual variation among patients. In all cases, the selected course of action should be considered by the treating provider in the context of treating the individual patient. Use of the information is voluntary. AAN provides this information on an "as is" basis, and makes no warranty, expressed or implied, regarding the information. AAN specifically disclaims any warranties of merchantability or fitness for a particular use or purpose. AAN assumes no responsibility for any injury or damage to persons or property arising out of or related to any use of this information or for any errors or omissions.

\section{CONFLICT OF INTEREST}

The American Academy of Neurology is committed to producing independent, critical, and truthful practice advisories. Significant efforts are made to minimize the potential for conflicts of interest to influence the recommendations of this practice advisory. To the extent possible, the AAN keeps separate those who have a financial stake in the success or failure of the products appraised in the practice advisories and the developers of the practice advisories. Conflict of interest forms were obtained from all authors and reviewed by an oversight committee prior to project initiation. AAN limits the participation of authors with substantial conflicts of interest. The AAN forbids commercial participation in, or funding of, practice advisory projects. Drafts of the practice advisory have been reviewed by at least $3 \mathrm{AAN}$ committees, a network of neurologists, Neurology peer reviewers, and representatives from related fields. The AAN Guideline Author Conflict of Interest Policy can be viewed at www.aan.com. For complete information on this process, access the 2011 AAN process manual. ${ }^{6}$

Received June 24, 2015. Accepted in final form December 30, 2015. 


\section{REFERENCES}

1. Murray CJ, Atkinson C, Bhalla K, et al; US Burden of Disease Collaborators. The state of US health, 19902010: burden of diseases, injuries, and risk factors. JAMA 2013;310:591-608.

2. Tuttolomondo A, Di Raimondo D, Di Sciacca R, et al. Arterial stiffness and ischemic stroke in subjects with and without metabolic syndrome. Atherosclerosis 2012;225:216-219.

3. Clark IA, Alleva LM, Vissel B. The roles of TNF in brain dysfunction and disease. Pharmacol Ther 2010; 128:519-548.

4. Tobinick E. Deciphering the physiology underlying the rapid clinical effects of perispinal etanercept in Alzheimer's disease. Curr Alzheimer Res 2012;9:99-109.

5. Tuttolomondo A, Pecoraro R, Pinto A. Studies of selective TNF inhibitors in the treatment of brain injury from stroke and trauma: a review of the evidence to date. Drug Des Devel Ther 2014;8:2221-2238.

6. American Academy of Neurology. Clinical Practice Guideline Process Manual, 2011 ed. Available at: https://www. aan.com/Guidelines/Home/Development. Accessed June 15, 2013, and February 20, 2015.

7. Clark I. New hope for survivors of stroke and traumatic brain injury. CNS Drugs 2012;26:1071-1072.

8. Tobinick E, Rodriguez-Romanacce H, Levine A, Ignatowski TA, Spengler RN. Immediate neurological recovery following perispinal etanercept years after brain injury. Clin Drug Investig 2014;34:361-366.

9. Tobinick E. Rapid improvement of chronic stroke deficits after perispinal etanercept: three consecutive cases. CNS Drugs 2011;25:145-155.
10. Tobinick E, Kim NM, Reyzin G, RodriguezRomanacce H, DePuy V. Selective TNF inhibition for chronic stroke and traumatic brain injury: an observational study involving 629 consecutive patients treated with perispinal etanercept. CNS Drugs 2012;26: 1051-1070.

11. Sackett DL. Bias in analytic research. J Chron Dis 1979; 32:51-63.

12. Maclean N, Pound P. A critical review of the concept of patient motivation in the literature on physical rehabilitation. Soc Sci Med 2000;50:495506.

13. Barnett AG, van der Pols JC, Dobson AJ. Regression to the mean: what it is and how to deal with it. Int J Epidemiol 2005;34:215-220.

14. Friedman JH, Dubinsky R. Patient page: the placebo effect. Neurology 2008;71:e25-e26.

15. Senabre-Gallego JM, Santos-Ramírez C, SantosSoler G, et al; AIRE-MB group. Long-term safety and efficacy of etanercept in the treatment of ankylosing spondylitis. Patient Prefer Adherence 2013;7: 961-972.

16. Butchart J, Brook L, Hopkins V, et al. Etanercept in Alzheimer disease: a randomized, placebo-controlled, double-blind, phase 2 trial. Neurology 2015;84: 2161-2168.

17. GoodRx Web Site. Available at: http://www.goodrx.com/ enbrel?gclid=CPnW68HPzroCFU9o7AodAAgAHA\#/?filterlocation $=$ Enter + your $+\mathrm{ZIP}+$ code $\&$ coords $=$ \&label $=$ Enbrel \&form $=$ syringe\&strength $=25 \mathrm{mg} \&$ quantity $=$ custom\&qtycustom $=5$. Accessed December 7, 2015. 


\section{Neurology}

\section{Practice advisory: Etanercept for poststroke disability: Report of the Guideline Development, Dissemination, and Implementation Subcommittee of the American Academy of Neurology}

Gary S. Gronseth and Steven R. Messé

Neurology 2016;86;2208-2211

DOI 10.1212/WNL.0000000000002735

\section{This information is current as of June 6, 2016}

\section{Updated Information \& Services}

Supplementary Material

\section{References}

Citations

Subspecialty Collections

Permissions \& Licensing

Reprints including high resolution figures, can be found at: http://n.neurology.org/content/86/23/2208.full

Supplementary material can be found at: http://n.neurology.org/content/suppl/2016/06/04/WNL.0000000000002 735.DC1

http://n.neurology.org/content/suppl/2016/06/04/WNL.0000000000002 735.DC2

This article cites 15 articles, 2 of which you can access for free at: http://n.neurology.org/content/86/23/2208.full\#ref-list-1

This article has been cited by 1 HighWire-hosted articles: http://n.neurology.org/content/86/23/2208.full\#\#otherarticles

This article, along with others on similar topics, appears in the following collection(s):

All Cerebrovascular disease/Stroke

http://n.neurology.org/cgi/collection/all_cerebrovascular_disease_strok e

\section{All Rehabilitation}

http://n.neurology.org/cgi/collection/all_rehabilitation

Information about reproducing this article in parts (figures,tables) or in its entirety can be found online at:

http://www.neurology.org/about/about_the_journal\#permissions

Information about ordering reprints can be found online:

http://n.neurology.org/subscribers/advertise

Neurology ${ }^{\circledR}$ is the official journal of the American Academy of Neurology. Published continuously since 1951, it is now a weekly with 48 issues per year. Copyright @ 2016 American Academy of Neurology. All rights reserved. Print ISSN: 0028-3878. Online ISSN: 1526-632X.

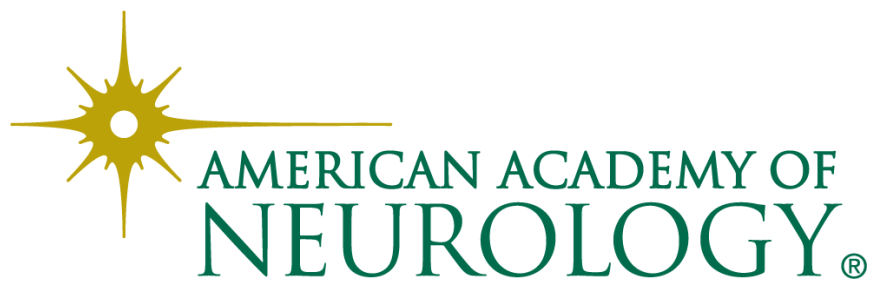

